\title{
Figure embeddedness depends on contour orientation
}

\author{
STUART APPELLE \\ State University of New York at Brockport, Brockport, New York 14420
}

\begin{abstract}
The "oblique effect" was studied using an embedded figures task in which complex patterns and hidden forms were rotated into different orientations. One set of stimuli (Series I) used patterns consisting either entirely of (depending on rotation) horizontal and vertical line segments or entirely of obliques. A second set of stimuli (Series II) used patterns composed of horizontal, vertical, and oblique segments in equal proportions. With Series I, both form and complex pattern orientations changed with rotation. In Series II, rotation changed the orientation of the hidden forms, but not the relative proportion of contour orientations in the complex patterns. Significantly longer search times were required to find forms embedded within the obliquely oriented patterns of Series I. There were no significant differences in Series II. These results are discussed in terms of the role contextual contours may play in the detection of differently oriented form:
\end{abstract}

ror a wide variety of visual tasks, performance is poorest when stimuli are presented in oblique orientations (i.e.. the "oblique effect"; see Appelle, 1972). Oblique effects in man are most closely associated with a reduced acuits or sensitivity to diagonally oriented test patterns. This deficit seems to reflect neuronal rather than dioptric properties (Campbell, Kulikowski. \& Levinson. 1966; Maffei \& Canipbell. 1970) and is most frequently attributed to modification of the visual nervous system by exposure in early experience to "carpentered" environments predominating in horizontal and vertical (H-V) contours (Annis \& Frost. 1973; Mansfield. 1974; Mitchell. Freeman. Millodot. \& Haegerstrom, 1973; Sekular, 1974). It is felt that exposure to such an environment modifies the neurophysiology underlying orientation perception so that these neuronal mechanisms develop biases corresponding to those tound in experience.

Since normal visual experience is characterized by III) uts disproportionately ricli in $\mathrm{H}-\mathrm{V}$ contours. observers might be expected to have difficult where complex visual fields predominate in obliyuels oriented contours. However, the effect of visuat field (contextual) orientations on form perception has not been tested experimentally. The oblique effect has been studied almost exclusively with discrete stimuli appropriate to single-unit feature-analyzer models of detection (bars of light. sinusoidal resolution gratings. etc.) rather than the more complex (and ecologically relevant) stimulus and performance variables associated with experience. The experiments reported nere stem from these considerations.

To assess the effect of the prevailing (contextual) isual field on the perception of form. a variation of

This research was supported in part by State Univesuly of Nen York Grants 022-7168A and 022-7168B. Requests for reprints should be addressed to the author. Department of Psychology. S.U.N.Y. at Brockport. Brockport. New York 14420. the embedded figures paradigm was used. This procedure measures a person's ability to detect simple forms located within more complex visual displays. The object of search is embedded, or hidden in, a complex stimulus pattern made up of line segments in various orientations. The task is a kind of figure-ground discrimination, where performance is measured by the search times required to segregate the forms from a series of complex patterns.

The standardized embedded figures tests (Educational Testing Service. 1962; Gottschaldt, 1926; Witkin. 1950) use test items in which both hidden form and complex pattern consist of line segments in various orientations. Since there is no systematic manipulation of the orientations comprising these patterns. they are not suitable for studying the specific effect of orientation. In the present study, stimuli were designed which controlled for the orientation of the component line segments. These stimuli could be rotated $45^{\circ}$ so that detectability of the embedded forms could be measured for identical patterns varying only in contour orientation.

One set of stimuli (Series I) used patterns in which component contours were of only one kind of orientation (either all H-V or all oblique. depending on rotation). Another set of stimuli (Series II) used patterns in which $\mathrm{H} \cdot \mathrm{V}$ and oblique segments were present in equal proportions. With the former stimuli, rotation of the test item changed the orientation of both the hidden form and the line segments in the complex pattern. With the latter stimuli, rotation of the test items eftectively changed only hidden form orientation (despite rotation. the relative proportion of $\mathrm{H}-\mathrm{V}$ to oblique segments remained invariant for the complex patterns). Therefore. performance differences with Series 1 could be ascribed to either hidden Iorm orientation or the orientation of the visual displat within which the forms were embedded. But with Series Il. pertormance differences could be ascribed only to the urientation of the object of search. 
By comparing performance on both sets of stimuli, the roles of form and field orientation was assessed.

\section{METHOD}

\section{Subject}

Fifty undergraduate students from the college population with no clinically detectable astigmatism volunteered to serve as subjects.

\section{Stimuli and procedure}

Test items were presented successively on $10.9 \times 14 \mathrm{~cm}$ white cards which were positioned on a table-mounted clipboard. Each test item consisted of a $4.25-\mathrm{cm}$-diam complex stimulus pattern (of which the hidden form was a part) and the isolated simple form $2.15 \mathrm{~cm}$ below. The hidden forms appeared on the same cards as the complex patterns to avoid introducing a memorial component in to the task, a factor which may underlie some oblique effects. No head restraint was used, but subjects were cautioned against head movements, and none were observed during testing.

Two series of test items were designed (see Figure 1). The test items were constructed on the basis of pilot data so as to cover a range of difficulties similar to that reported by Witkin (1950). In Series I, the complex stimulus patterns were composed of line segments $90^{\circ}$ apart in orientation. By rotating the entire test item (both hidden form and complex display ) $45^{\circ}$, each pattern could be presented in either a $\mathrm{H}-\mathrm{V}$ format (all component line segments either horizontal or vertical) or in an oblique format (all component line segments $135^{\circ}$ or $45^{\circ}$ obliques). The patterns in Series I were designed so that total line length of segments in one orientation (e.g., horizontal) was equal to total line length of the orthogonal segments (e.g., vertical). In Series II, the complex fields consisted of an equal proportion of both $\mathrm{H}-\mathrm{V}$ and oblique lines presented together (total line length for $\mathrm{H}-\mathrm{V}$ segments was equal to the oblique segments).

In each series, the same four hidden forms were used (see Figure 1). Each of these forms was embedded within two different

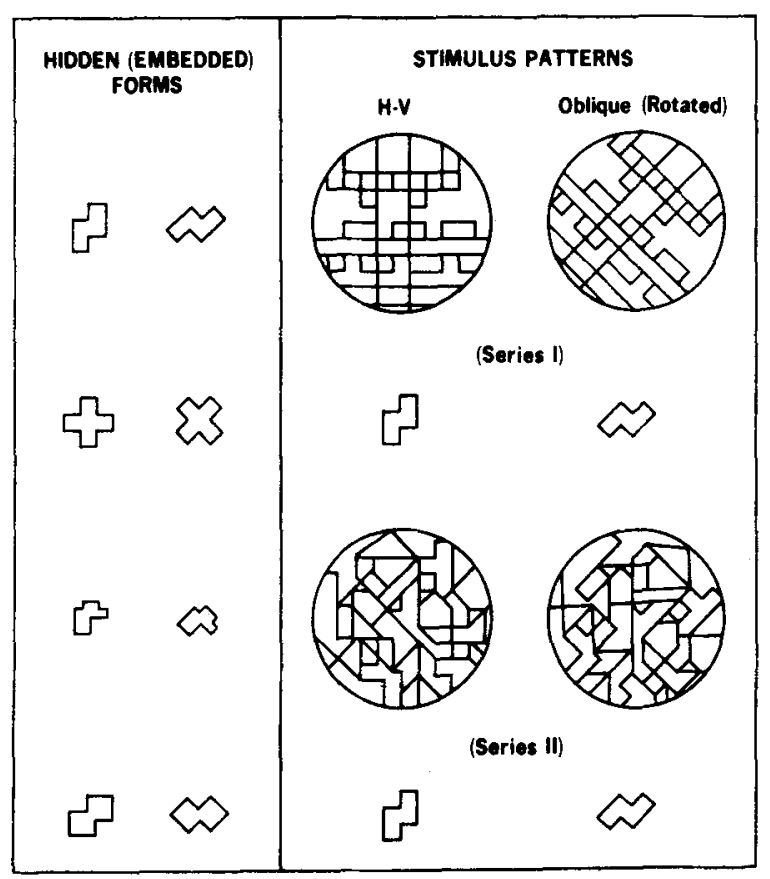

Figure 1. Hidden forms and examples of complex patterns used in Series I and Series II. complex patterns so that there were eight basic test items in each series. These eight basic patterns were presented twice, once in the $\mathrm{H}-\mathrm{V}$ format and once in the oblique format (for a total of 16 trials per test series). The order of presentation for test patterns was completely randomized, and counterbalancing was used to control for the sequence in which the $\mathrm{H}-\mathrm{V}$ and oblique versions of each test pattern appeared. One restriction on the randomization procedure was that no basic test pattern could be followed immediately in the series by its rotated counterpart.

Thirty subjects were tested on Series I and 20 subjects were tested on Series II. A sample practice trial was used to insure that all subjects understood the instructions. Consistent with the procedure used by Witkin (1950), a ceiling of $300 \mathrm{sec}$ was imposed on each trial (this was necessary on only $3 \%$ of all trials on Series I and $5 \%$ of all trials on Series II). "Errors" were rare, but where they occurred subjects were told they were incorrect and instructed to continue. Search times were recorded with a stopwatch.

\section{RESULTS}

Two-factor ANOVAs (orientation and test pattern) indicate no difference between mean search times, $F(1,19)<1$, as a function of orientation on Series II (61.2 sec for H.V patterns; $61.6 \mathrm{sec}$ for the obliques), but a highly significant effect for orientation with Series I, $F(1,29)=8.22, p<.01$. On Series I, mean search times for oblique test patterns $(67.5 \mathrm{sec})$ were $33.9 \%$ longer than mean search times $(50.4 \mathrm{sec})$ on the $\mathrm{H}-\mathrm{V}$ presentations. There was a significant main effect for test pattern in both Series I, F(7,203) = $10.24, \mathrm{p}<.01$, and Series II, $F(7,133)=5.67$, $\mathrm{p}<.01$, but this simply reflects the intended variance in baseline difficulty among the eight basic test patterns and is of no theoretical importance.

The interaction between pattern and orientation was not significant in either series. Ordinarily, this interaction would be an appropriate measure of consistency in the orientation factor across test patterns. However, because the test patterns are inherently different from each other in absolute difficulty, the absolute differences between obliques and $\mathrm{H}-\mathrm{Vs}$ (which is what the ANOVA interaction compares) are associated with the baseline difficulty of each pattern. The interaction, therefore, does not measure the more meaningful variance in the relative difficulties of obliques and H-Vs. As another measure of consistency, the frequency for which the oblique version of each test pattern required longer search times than its $\mathrm{H}-\mathrm{V}$ pair was compared with the frequency for which the $\mathrm{H}-\mathrm{V}$ version took longer than its oblique counterpart. Simply using a binomial test, there was a significantly greater overall frequency for the oblique versions taking longer on Series I $(p<.01)$. Using McNemar's (1962) chi-square test for correlated proportions, it was found that this frequency did not vary $(p>.05)$ with either test patterns $\left(\chi^{2}=6.45, \mathrm{df}=7\right)$ or hidden forms $\left(\chi^{2}=\right.$ 5.34 , df $=3$ ). There were no significant differences on either the binomial or chi-square tests for Series II. These tests indicate that the oblique effect (or lack of it in Series II) was consistent across test patterns. 
Table 1

Mean Search Time (Seconds) and Standard Error of the Mean as a Function of Test Item Orientation and Order of Presentation (Pre- vs. Postrotation Trials)

\begin{tabular}{|c|c|c|c|c|c|c|c|c|}
\hline \multirow{3}{*}{$\begin{array}{c}\text { Orienta- } \\
\text { tation }\end{array}$} & \multicolumn{4}{|c|}{ Series I $(N=30)$} & \multicolumn{4}{|c|}{ Series II $(N=20)$} \\
\hline & \multicolumn{2}{|c|}{$\begin{array}{c}\text { Pre- } \\
\text { Rotation }\end{array}$} & \multicolumn{2}{|c|}{$\begin{array}{c}\text { Post- } \\
\text { Rotation }\end{array}$} & \multicolumn{2}{|c|}{$\begin{array}{c}\text { Pre- } \\
\text { Rotation }\end{array}$} & \multicolumn{2}{|c|}{$\begin{array}{c}\text { Post- } \\
\text { Rotation }\end{array}$} \\
\hline & Mean & $\sigma_{\overline{\mathbf{x}}}$ & Mean & $\sigma_{\overline{\mathbf{x}}}$ & Mean & $\sigma_{\overline{\mathbf{x}}}$ & Mean & $\sigma_{\overline{\mathbf{x}}}$ \\
\hline & & 0 & & 7. & & 10 & & 7.7 \\
\hline & 61.3 & 8.9 & 39.5 & 5.8 & 70.6 & 10.2 & 51.8 & 8.0 \\
\hline
\end{tabular}

Another consideration is the effect of practice (i.e., experience or familiarity). On both series, the typical trial-by-trial overall reduction in search time (see Goldstein \& Chance, 1965) was apparent. In the present context, however, the more direct concern is with the oblique effect itself. Since each basic test pattern was presented twice to each subject (once before and once after rotation), the effect of orientation on pre- and postrotation trials can be compared. On a subjective basis, postexperimental interviews revealed that almost all the subjects were completely unaware that the test series consisted of pairs of identical patterns differing only in orientation. Subjectively, each test item was a new and distinct stimulus. Nevertheless, an inspection of the data in Table 1 suggests that the oblique effect which appeared in Series $I$ is reduced with practice. Comparing only prerotation trials, the oblique versions of the test patterns required $41.9 \%$ longer search times than the H-V versions. When comparing only the later presentations (after rotation), the oblique effect is reduced to $21.5 \%$. An ANOVA indicated that the order of appearance (pre- vs. postrotation trials) was significant in both Series I, $\mathrm{F}(1,29)=29.27, \mathrm{p}<.01$. and Series II, $\mathrm{F}(1,19)=$ 4.88. $\mathrm{p}<.05$, with the prerotation trials requiring longer search times than the rotated second presentations. Again, the main effect for orientation was significant only in Series I, $F(1.29)=7.18$, $\mathrm{p}<.05$.

The interaction between the orientation factor and practice was not significant in either series $(F<1)$. However, since the meaningfulness of these interactions is subject to the same questions raised in regard to the interaction with test patterns, McNemar's chi-square test was used to compare preand postrotation trials for frequency of oblique effect occurrence. This also showed no significant change in the orientation factor. Thus, while practice (experience, familiarity) reduces overall search time, it does not significantly reduce the oblique effect.

\section{DISCUSSION}

Two series of embedded stimuli were used to study the roles of object and contextual orientations in detecting hidden forms. In Series I, each test item could be rotated so that the pattern and hidden form consisted either entirely of oblique line segments or entirely of $\mathrm{H} \cdot \mathrm{V}$ segments. Subjects required significantly more time for finding the oblique forms within the obliquely oriented patterns than for finding the $\mathrm{H}-\mathrm{B}$ forms within the $\mathrm{H}-\mathrm{V}$ patterns. Test items in Series II consisted of patterns containing oblique and $\mathrm{H}-\mathrm{V}$ components in equal proportion. Rotation of these test items changed the orientation of the hidden forms, but the proportion of oblique and $: \mathrm{H}-\mathrm{V}$ components in the pattern remained invariant. Here, search time did not change with the orientation of the hidden forms. This failure to obtain an oblique effect suggests that orientations comprising the object's contextual field were more critical to performance than the orientation of the object itself.

This raises some questions as to the influence of contextual orientation over a wide range of relative proportions. In the present study, only two proportions were used; one in which $50 \%$ of the contextual array was in the same orientation as the hidden form and one in which $100 \%$ of the array components were aligned with the target's orientation. The change in these two conditions, from no oblique effect to a highly significant one, is subject to a number of interpretations. It is possible that the data reflect the unique case of displays in which all contextual contours are aligned with the hidden form, and that mixed contexts of any proportion (not just $50 \%$ ) would fail to produce an oblique effect.

Another interpretation stems from early work on gestalt laws of organization underlying "embeddedness" and more recent studies on perceptual grouping (Beck. 1966a, b). These would suggest that as the proportion of contextual contour aligned with the hidden form increases, the embeddedness of the form should also increase. Since the proportion of aligned contours increased (from Series Il to Series I) by the same amount for both the $\mathrm{H}-\mathrm{V}$ and oblique hidden forms. the appearance of an oblique effect in Series I may reflect a more gradual slope in the influence of $\mathrm{H}-\mathrm{V}$ contexts on $\mathrm{H}-\mathrm{V}$ forms than oblique contexts have on the embeddedness of oblique forms. The shape of these functions could conceivably be complex, however. For example, a situation in which no contextual contours were of the orientation of the hidden form could become functionally equivalent to measuring reaction times to isolated targets (since the hidden form becomes immediately apparent without any real "search"). Reaction time measures have produced oblique effects before (Furchner \& Young, 1975).

A validation of these interpretations will wait upon the design of an extensive series of stimuli, in which the proportion of aligned contextual elements varies from 0 to 1.0 systematically. While the experiments reported here, in using just two proportions, cannot 


\section{APPELLE}

decide between these alternatives, it points out the importance of context in assessing the role of orientation in form perception. A recent experiment by Weisstein and Harris (1974) showed that contexts which take on the appearance of unified three-dimensional configurations improve detection of a single component line. Their study demonstrated the importance of configuration in contextual displays. The present study demonstrates the importance of orientation in contextual displays. These types of experiment make a case for studying the role of context in perception, and demonstrate the limitations of studying contours as isolated stimuli.

\section{REFERENCES}

Annis, R. C., \& Frost, B. Human visual ecology and orientation anisotropies in acuity. Science, 1973, 182, 729-731.

Appelie, S. Perception and discrimination as a function of stimulus orientation: The "oblique effect" in man and animals. Psychological Bulletin. 1972. 78. 266-278.

BECK. J. Effect of orientation and of shape similarity on perceptual grouping. Perception \& Psychophysics, 1966, 1, 300-302. (a)

BECK. J. Perceptual grouping produced by changes in orientation and shape. Science. 1966, 154. 538-540. (b)

Campbell. F. W., Kulikowsis. J. J., \& Levinson, J. The effect of orientation on the visual resolution of gratings. Journal of Physiology, 1966. 187. 427-436.
Educational. Testing Service. Hidden figures tests $C F-1$ and Form V. Educational Testing Service. Princeton, New Jersey, 1962.

Furchner, C. S.. \& Young, S. J. Recovery from adaptation as a function of stimulus orientation. Perception \& Psychophysics, 1975. 17, 117.124

Goldstein. A. G.. \& Chance, J. E. Effects of practice on sex-related differences in performance on embedded figures. Psychonomic Science, 1965. 3, 361-362.

Gottschaldt. K. Über den Einfluss der Erfahrung auf die Wahrnehmung von Figuren. Psychologische Forshung, 1926, 8, 261-317.

Maffel. L., \& Campbell, F. W. Neurophysiological localization of the vertical and horizontal visual coordinates in man. Science. 1970. 167. 386-387.

Mansfield, R. J. W. Neural basis of orientation perception in vision. Science, 1974, 186, 1133-1135.

McNemar. Q. Psychological statistics. New York: Wiley, 1962.

Mitchell, D. E.. Freeman, R. D., Millodot, M., \& HAEgerstrom. G. Merdional amblyopia: Evidence for moditication of the human visual system by early visual experience. Vision Research, 1973, 13, 535-558.

Sekular. R. Spatial vision. Annual Review of Psychology. 1974, 25. 195-232.

Weisstein. N..\& Harris. C. S. Visual detection of line segments: An object-superiority effect. Science, 1974, 186, 752-754.

WITKIN, H. A. Individual differences in ease of perception of embedded figures. Journal of Personality, 1950, 19, 1-15.

(Received for publication June 4, 1975; revision received October 17,1975 .) 